\title{
HOUR VERSUS TEMPERATURE IN ANT SPECIES DIVERSITY IN FIELD RHYTHM
}

\author{
By Elwood S. McCluskey and Jack S. Neal* \\ Physiology and Biology Departments, respectively, \\ Loma Linda University, Loma Linda, California 92350
}

\section{INTRODUCTION}

The longstanding problem of sorting out correlated variables in field research is illustrated by a study of ant species diversity. Different ants are clearly above ground at different hours and temperatures; but is this in response to hour, or to temperature, or both? By discriminant analysis, ant nests were segregated to their respective species only if hour and temperature characters were considered simultaneously. This suggests that the definite species diversity earlier seen in constant laboratory temperature is modified by speciesspecific response to field temperature (or other information reflected in that variable). Note that the focus of the investigation is diversity in pattern, rather than pattern in a given species.

\section{Material AND Methods}

Six species were compared (see Fig. 2 legend). The 4 or 5 nests each were all in an area $0.2 \mathrm{~km}$ across, sloping gently southeast, near Thousand Palms (elevation $120 \mathrm{~m}$ ) in southern California desert. The nests were interspersed with respect to species, reducing replicate bias. The 9 observation days were within a 3-week period (February-March), minimizing season change to $0.3 \mathrm{~h}$ in sunrise time.

There were too many nests to observe simultaneously (a round took 1-2 h). So for discriminant analysis (e.g., Fig. 3) all counts for a nest over the hours of all the days were fitted by a Lowess curve (Cleveland 1985, Wilkinson 1988), which is not limited by assumption of a single underlying form, and works with unequally spaced $X$ (hour) as it smooths Y (log ant count). Eight "on-the-hour" counts were read from the curve as hour response variables $(0600$, $0700 \ldots 1300$ ), so that direct comparison could be made with other

\footnotetext{
*Present address: Route 3, Box 126, Willow Springs, MO 65793 Manuscript received by the editor March 24, 1990.
} 


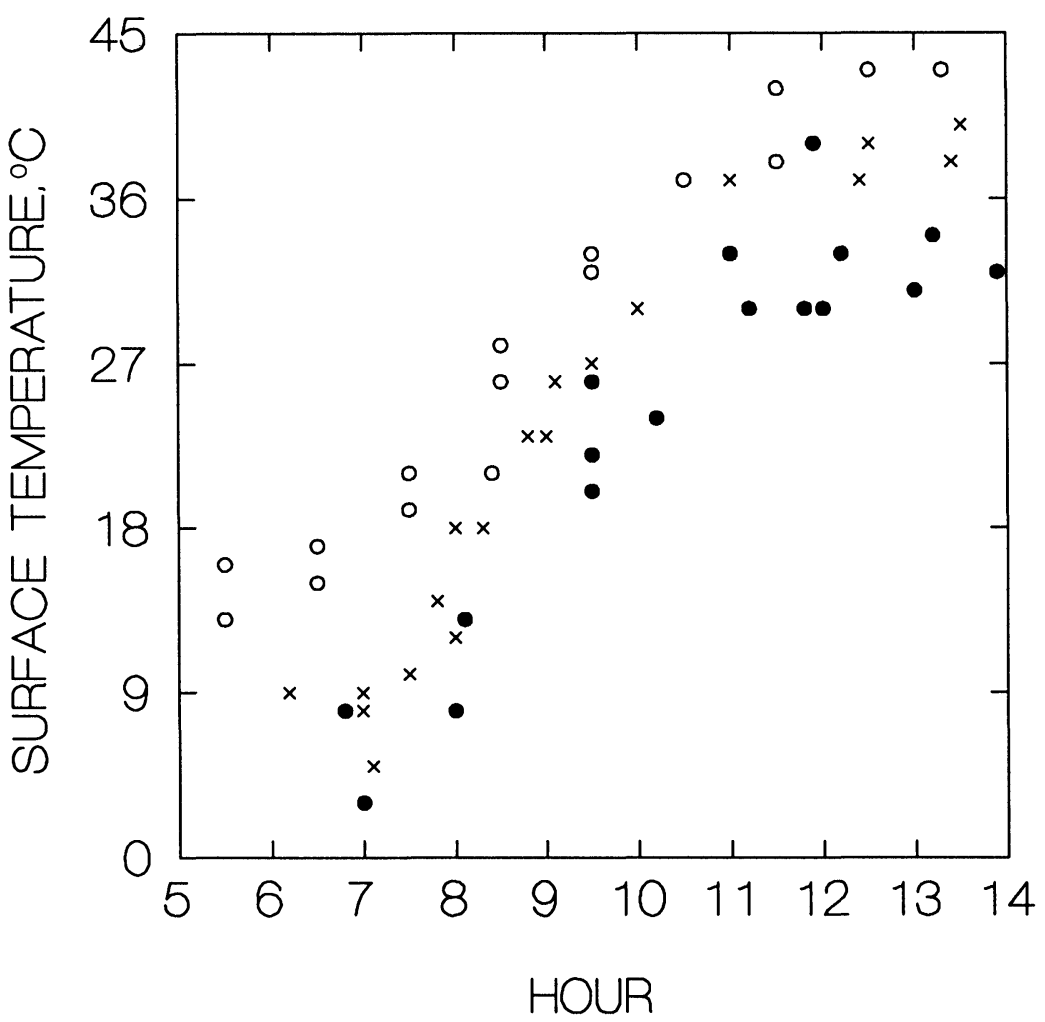

Fig. 1. Environmental hour-temperature relation on the 9 observation days; 3 coolest $(\bullet)$ and 3 warmest $(O)$ days marked to show days used in Fig. 2. Glass mercury thermometer on surface of non-shaded ground (also at $7 \mathrm{~cm}$ deep, not shown).

nests. (Method was checked by treating above on-the-hour counts for all replicate nests of a species as 1 group for fitting a Lowess curve: the resultant species curve for any given species was almost identical to a species curve derived directly from original counts.) The same method was used for surface temperature, with curve fitted to counts over the temperatures; 8 "on-the-temperature" response variables $\left(9,12,16,23,29,34,37,40^{\circ} \mathrm{C}\right)$ were chosen to span the range of environmental temperature and to correspond to the 8 hour variables. Deep-temperature response variables were derived in a similar way: $10,12,14,16,19,22,25,28^{\circ} \mathrm{C}$. 
In view of the high correlation between environmental temperature and hour (Fig. 1), how could response variables to these factors be distinguished?

1) Only morning observations were used, to avoid complications due to darkness-versus-light and to reversal from rising to falling temperature.

2) Some days were much warmer than others, thus partly decoupling temperature from hour.

3) On the other hand, this makes it hard to interpret hour response variables - they were against a different temperature background every day. But in one case some uniformity was provided by combining counts for all the replicates of a species to give enough information to analyze the 3 warmest days separately from the 3 coolest days (Fig. 2).

4) Another approach was discriminant analysis. It considers responses (here, to temperature-hour environment) as a whole, using dependent (and often correlated) variables in concert. On the basis of known group membership it weights the variables so as to discriminate optimally among the groups (here, species) (Cooley \& Lohnes 1971). Thus it could be used to test the variables for their part in diversity.

Because conclusions are little better than the underlying replication (see Hurlbert 1984 for field studies), the types of "replicates" are listed. Though more than sometimes seen in field work, they were sufficient only for the exploratory analysis intended (see Williams \& Titus 1988 for multivariate studies):

Nests within species (Fig. 3).

Species within profile analysis (Fig. 2).

Coolest versus warmest days (Fig. 2).

Profile comparison (Fig. 2) versus discriminant analysis (Fig. 3).

Subgroups of variables in discriminant analysis (Fig. 3).

\section{RESULTS}

The most direct approach was to compare profiles shown as hour response with those shown as temperature response (Fig. 2). By either criterion the species patterns were distinctive. For example, the maxima for the bottom species were some $4 \mathrm{~h}$ later and $20^{\circ} \mathrm{C}$ 


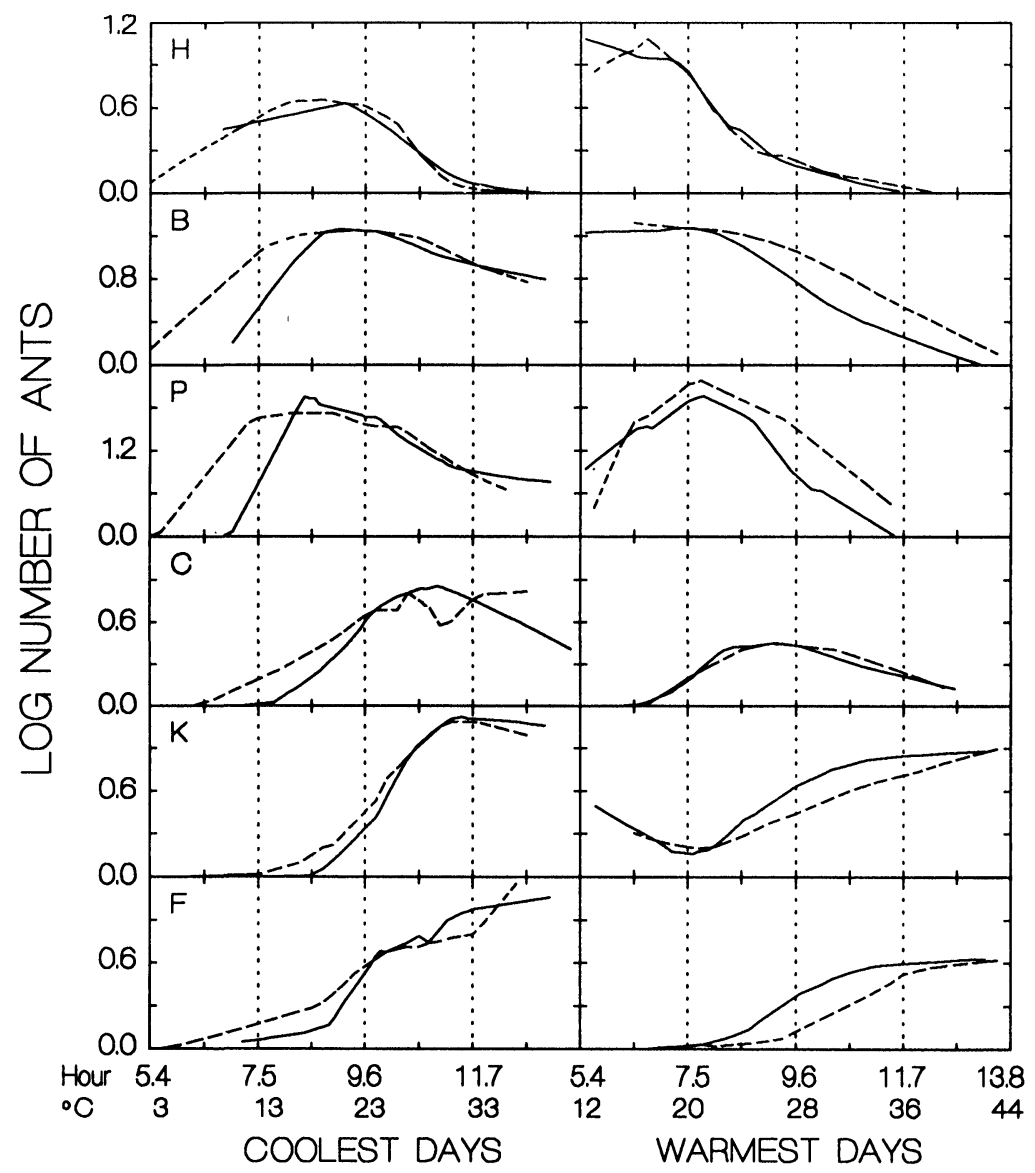

Fig. 2. Close correlation between responses (number of ants within $0.5 \mathrm{~m}$ of nest entry) plotted in terms of hour (-) and of surface temperature (- -). To make such biological comparison unbiased, relation between hour and temperature scales on $\mathrm{X}$ axis was derived directly from environmental hour-temperature correlation. The 3 COOLEST and 3 WARMEST days (see Fig. 1) form 2 independent checks of this comparison. Letter in corner of each panel: $\mathrm{B}=$ Conomyrma bicolor, $\mathrm{C}=$ Pogonomyrmex californicus, $\mathrm{F}$ and $\mathrm{K}=$ Myrmecocystus flaviceps and kennedyi, $\mathrm{H}=$ Pheidole barbata, $\mathrm{P}=$ Messor pergandei (ants from 3 different subfamilies). Counts for all replicate nests of a species were treated as 1 group and fitted by a Lowess curve. (Checking method by assigning half the replicates of each species to wrong species made hour-temperature correlation poor.) 
higher than for the top ones (a big difference to an observer out in the sun!).

But Fig. 2 shows how much alike the hour and temperature response patterns were for any one species. Even though ants were out earlier on the warmest than on the coolest days, there was the same detailed, species-specific correlation between hour and surface temperature response patterns.

What could be done to separate temperature from hour variables? And central to the main topic here, how might enough species differences be found in just an 8-hour segment of the day to distinguish all 6 species? Discriminant analysis (Fig. 3) was used 1) to compare all species simultaneously, and hence 2) to test how completely they might be segregated by using many dependent variables. Either 8 hour, or 8 surface-temperature, or 8 deep-temperature response variables were tested. (It should be remembered that such a variable represents "response"-number out-of the ants at a particular hour or temperature.)

In each case the species means differed $(P<.001$ for multivariate analysis of variance). But the question here is beyond that: are the replicates completely segregated into their respective species? No, only partially by the 8 hour (Fig. $3 \mathrm{H}$ ) or 8 surface-temperature (Fig. $3 \mathrm{~S})$ variables, and even less by deep-temperature (not shown).

So combinations of 16 variables were tried, using more than one type at once. With surface-temperature + deep-temperature (Fig. 3SD) or hour + deep-temperature (not shown) 3 of the 6 species overlapped. But with hour + surface-temperature (Fig. 3HS) there was only slight overlap (between the 2 species that were in the same genus, Myrmecocystus).

Further testing was by stratified sampling of discriminant analyses based on the other possible combinations of 16 variables: all 8 of one type +4 each of the other two types. Segregation was good by the four combinations of 16 that included 8 hour and 4 surfacetemperature characters, but not by the eight other combinations tried; this supports the single-example illustration in Fig. 3 (panel HS versus panel SD).

\section{Discussion}

Reviews (McCluskey 1973, 1974) of early papers compared numerous species in terms of hour above ground. The following 
reports on field diversity all examine temperature as a prime factor (and all concern desert ants, as does the present report).

Peak foraging temperature is the same for 3 species of one genus, but $25^{\circ} \mathrm{C}$ lower for a species of another; high correlation of temperature with saturation deficit prevented distinguishing between these two factors (Whitford and Ettershank 1975). Of 13 species, the midpoint of foraging temperature is from below $20^{\circ} \mathrm{C}$ for one to above $40^{\circ} \mathrm{C}$ for others; also the range of temperature is species-specific (Bernstein 1979). Of 15 species, some are diurnal, others are nocturnal or switch to nocturnal when hot, with evidence for temporal control in many by temperature, in others by saturation deficit (Briese and Macauley 1980). The effect of shading on timing is much greater in one species than in two others (Smith, Smith, and Patten 1987). Of 36 species, ants come to baits at temperatures characteristic both of species and of genus (Morton and Davidson 1988). Of 10 species, 4 are strictly nocturnal or diurnal and hence related to light or hour (circadian); others relate more to temperature; there is a seasonal shift in foraging temperatures but little shift in daily species sequence (Heatwole and Muir 1989).

Except for the last report above, little mention is made of possible hour factors, as distinguished from temperature, and it is worth reviewing evidence from the present study.

With its unfailing day-night cycle, the field provided 1) a fixed hour pattern against which to evaluate responses to temperature. And the natural fluctuation between warm and cool days provided 2) the temperature variation necessary (Fig. 1).

But this very fluctuation meant there was not a fixed pattern against which to evaluate responses to hour. This was especially true when all 9 days, warm or cool, were used at once to give enough information to assay replicates individually (Fig. 3): the differences of temperature for a given hour might be enough to obscure differences among species.

Neverthless in discriminant analysis, hour responses appeared as important as surface-temperature responses in segregating species. And a combination of both was required (Fig. 3), as if complete scheduling information were not found in either type of character alone. "Hour" would include any variables that relate to the daily environmental cycle, or to an endogenous circadian cycle. "Temperature" would include the irregular component of weather beyond that related to hour. 


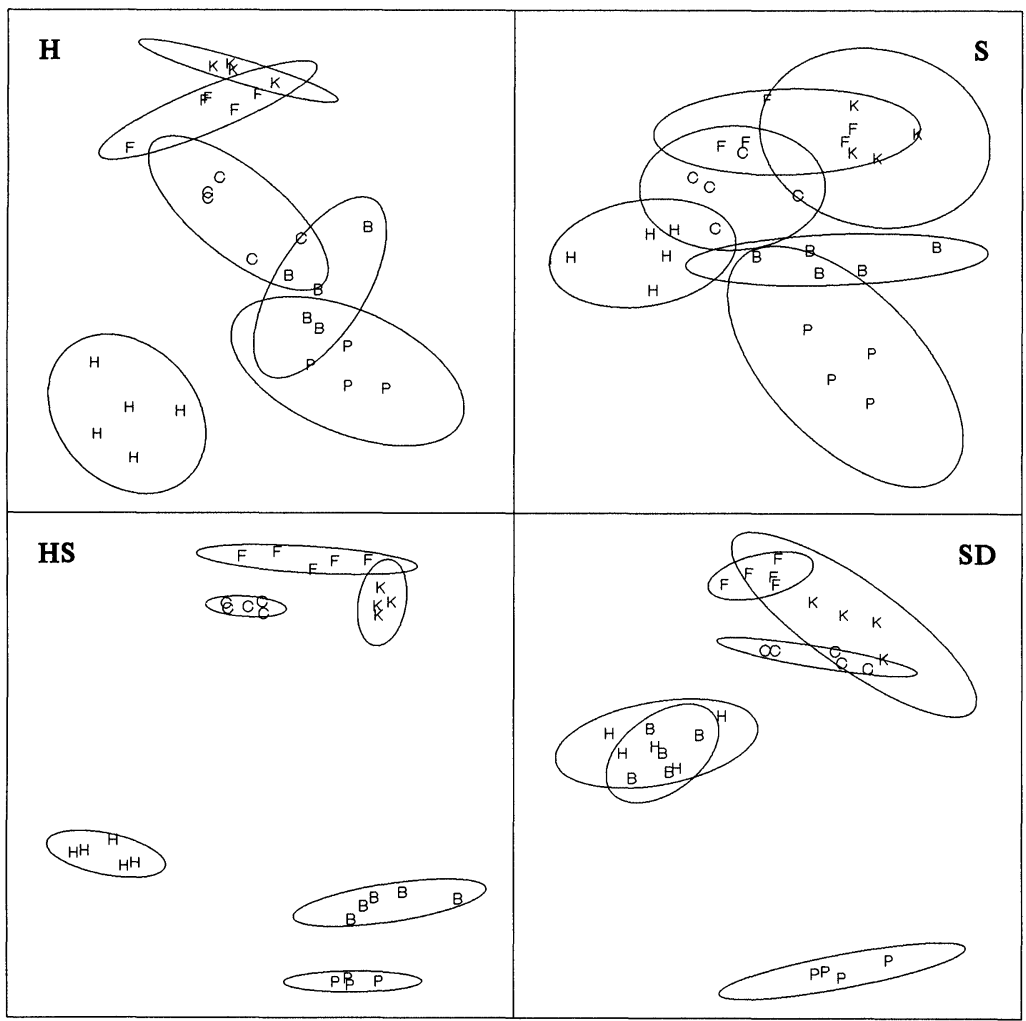

Fig. 3. Discriminant analyses of same ants as Fig. 2, but here based on all 9 days; 6 species (initials as Fig. 2), 4-5 replicate nests each; species ellipse $=95 \%$ confidence interval. Each panel based on different set of response variables: $\mathbf{H ,} 8$ hour; $\mathbf{S}, 8$ surface-temperature; HS, 8 hour +8 surface-temperature; SD, 8 surface-temperature +8 deep-temperature. For each panel, $\mathrm{Y}$-axis $=$ canonical variable $1, \mathrm{X}$-axis $=$ canonical variable 2. Note correct species assignment of replicates in HS, in sharp contrast to other panels.

It would be desirable to observe on days when the field temperature is constant; or in the laboratory. The latter had actually been done previously (McCluskey and Soong 1979), including 2 of the same species used here. Replicates were all segregated into their respective species by hour characters of the light part of the cycle, in the absence of any temperature cycle at all. Further, the species which would be out in the midday heat in the field, periodically chose the constantly hot region of the laboratory nests. But the 
patterns of rhythm were not the same as in the field, perhaps because of no temperature cycle (or because of artificial, workeronly nests). Some ants are rhythmic in the absence not only of a temperature cycle but also of the light-dark cycle (McCluskey 1987, North 1987).

In conclusion, control of temporal diversity evidently involves at least a circadian component and a temperature-related response component, both species-specific. This report hardly gives final answers. But it does suggest the challenge of investigation right in field conditions.

\section{SUMMARY}

The aim was to distinguish the effects of environmental variables, often difficult because of their high correlation. The diversity in daytime aboveground pattern of 6 species was almost the same whether the ant counts were organized in terms of hour or of temperature. But a combination of both hour and surfacetemperature response variables in discriminant analysis was required to assign all the nests to their respective species. The diversity in pattern might be explained by a circadian component plus heavy modification by temperature response, both species-specific.

\section{ACKNOWLEDGMENTS}

We thank R. R. Snelling for determining ant species, D. G. Kissinger and G. M. Scherba for reading the manuscript, and the Geoscience Research Institute for grant support. The SYSTATSYGRAPH package of microcomputer programs (Wilkinson 1988) was used, especially for its graphical analysis. Original data were from the Appendix of Neal (1985).

\section{Literature Cited}

Bernstein, R. A.

1979 Schedules of foraging activity in species of ants. Journal of Animal Ecology 48: 921-930.

Briese, D. T., AND B. J. Macauley

1980 Temporal structure of an ant community in semi-arid Australia. Australian Journal of Ecology 5: 121-134.

Cleveland, W. S.

1985 The elements of graphing data. Wadsworth, Monterey, California. 323 pp. 
COOLEy, W. W. AND P. R. LOHNES

1971 Multivariate data analysis. Wiley, New York. 364 pp.

Heatwole, H., and R. MuiR

1989 Seasonal and daily activity of ants in the pre-Saharan steppe of Tunisia. Journal of Arid Environments 16: 49-67.

HURLBERT, S. H.

1984 Pseudoreplication and the design of ecological field experiments. Ecological Monographs 54: 187-211.

MCCluskey, E. S.

1973 Generic diversity in phase of rhythm in formicine ants. Psyche 80: 295-304.

1974 Generic diversity in phase of rhythm in myrmicine ants. Journal of the New York Entomological Society 82: 93-102.

1987 Circadian rhythm in the tropical ant Ectatomma (Hymenoptera: Formicidae). Psyche 94: 245-251.

MCCluskey, E. S., AND S. A. Soong

1979 Rhythm variables as taxonomic characters in ants. Psyche 86: 91-102.

Morton, S. R., AND D. W. Davidson

1988 Comparative structure of harvester ant communities. Ecological Monographs 58: 19-38.

NeAL, J. S.

1985 Field behavioral comparison of eight species of California desert ants. M.A. thesis. Loma Linda University, Loma Linda, California. 111 pp.

NORTH, R. D.

1987 Circadian rhythm of locomotor activity in individual workers of the wood ant Formica rufa. Physiological Entomology 12: 445-454.

Smith, S. D., W. E. Smith, and D. T. Patten

1987 Effects of artificially imposed shade on a Sonoran Desert ecosystem: arthropod and soil chemistry responses. Journal of Arid Environments 13: $245-257$.

Whitford, W. G., AND G. EtTershank

1975 Factors affecting foraging activity in Chihuahuan desert harvester ants. Environmental Entomology 4: 689-696.

Williams, B. K., AND K. Titus

1988 Assessment of sampling stability in ecological applications of discriminant analysis. Ecology 69: 1275-1285.

WILKINSON, L.

1988 Sygraph; Systat: the system for statistics. Systat, Evanston, Illinois. 2 vol., $1744 \mathrm{pp}$. 

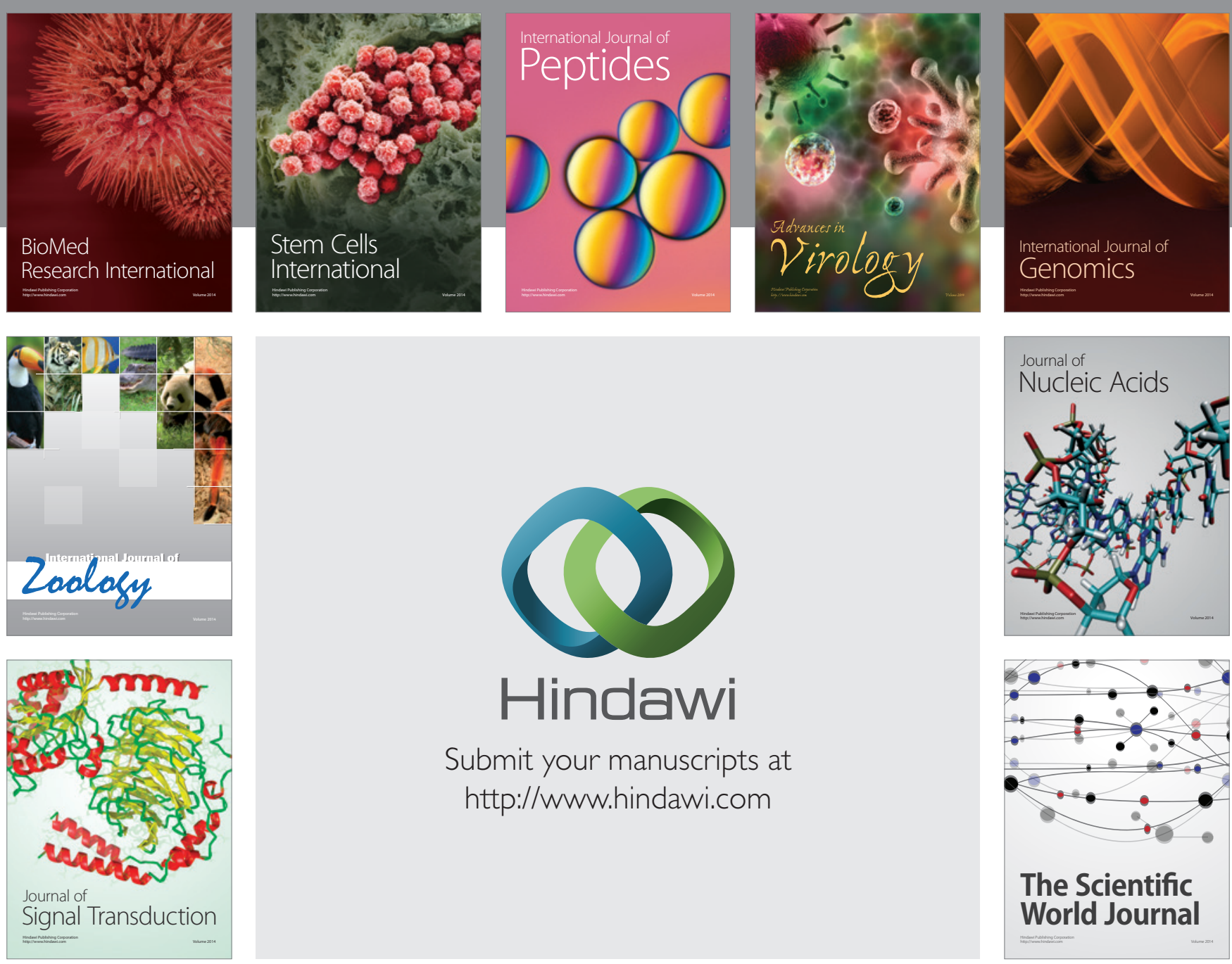

Submit your manuscripts at

http://www.hindawi.com
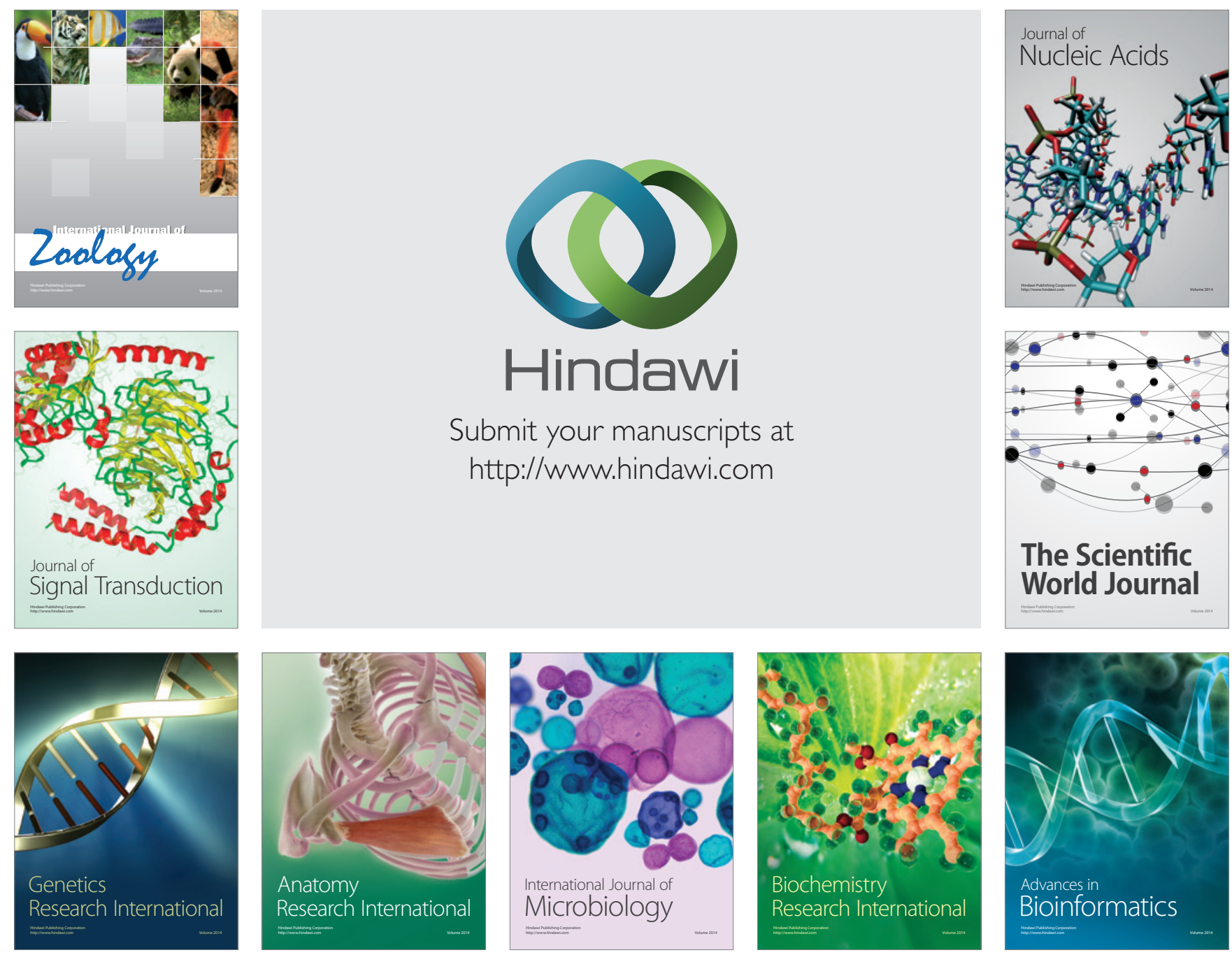

The Scientific World Journal
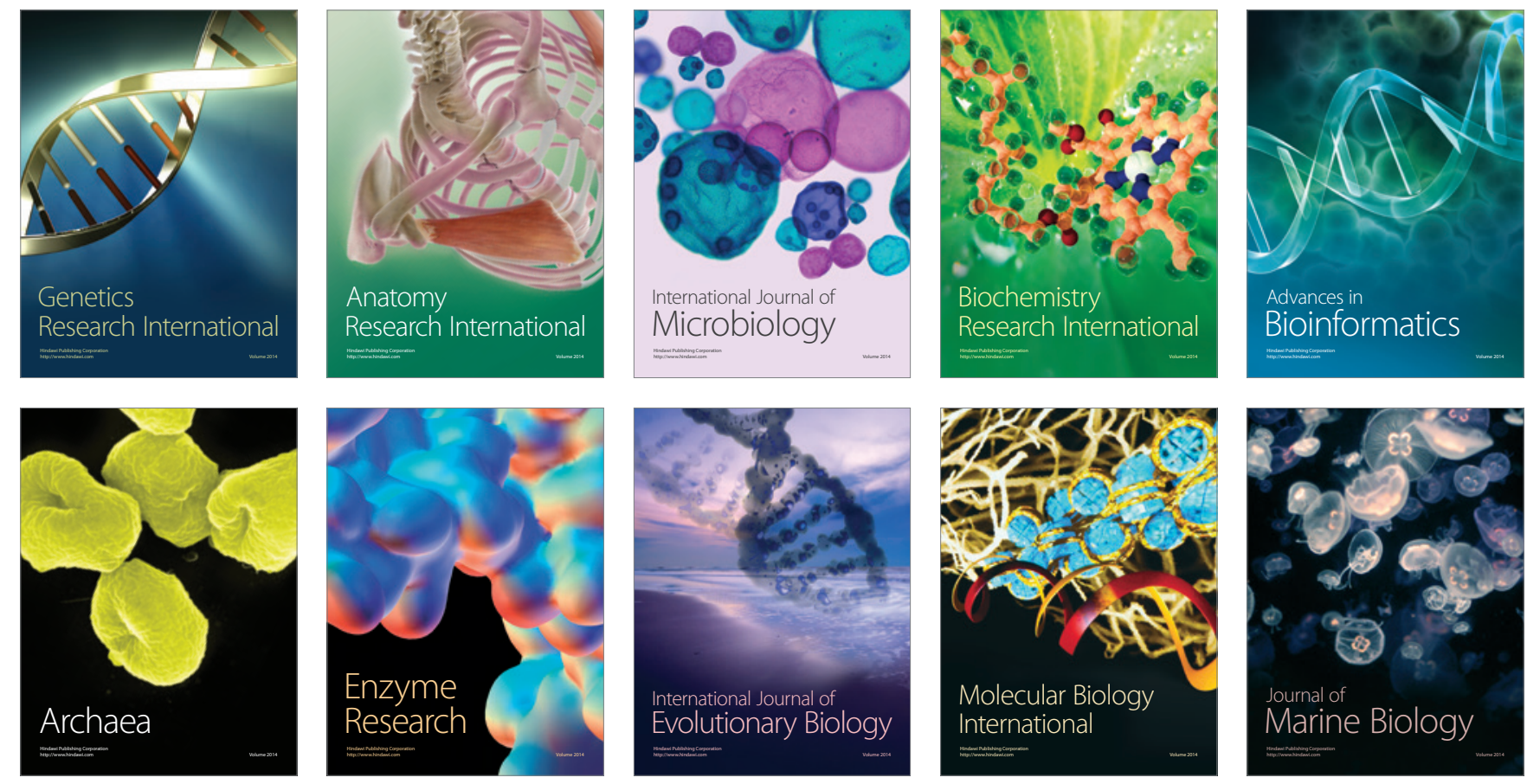